\title{
An Efficient Unicode based Sorting Algorithm for Bengali Words
}

\author{
Md. Ruhul Amin \\ Dept. of Computer \\ Science and Engineering, \\ Shahjalal University of \\ Science and Technology, \\ Sylhet-3114, Bangladesh
}

\author{
Asif Mohammed \\ Samir \\ Dept. of Computer \\ Science and Engineering, \\ Shahjalal University of \\ Science and Technology, \\ Sylhet-3114, Bangladesh
}

\author{
Madhusodan \\ Chakraborty \\ Dept. of Computer \\ Science and Engineering, \\ Shahjalal University of \\ Science and Technology, \\ Sylhet-3114, Bangladesh
}

\author{
Md. Mahfuzur \\ Rahaman \\ Dept. of Computer \\ Science and Engineering, \\ Shahjalal University of \\ Science and Technology, \\ Sylhet-3114, Bangladesh
}

\begin{abstract}
This discussion focuses on the sorting algorithm for Bengali language represented by Unicode character set. A few works has been done on this topics but no standard is set up yet to sort Bengali words. Some of these works are based on ASCII representation. To use ASCII, keyboard mapping is important because it is different for each country where the Unicode representation is fixed for all characters of various countries. So, Unicode representation is much more preferable than ASCII representation. In this paper we have discussed about an easy way to sort the Unicode Bengali texts. In our method, a mapping is used which simplified the sorting procedure. This method can sort any Unicode Bengali text and it is not keyboard dependent.
\end{abstract}

\section{General Terms}

Theoretical Informatics.

\section{Keywords}

Bengali Word Sorting, Unicode Bengali Sorting, Bengali Text Sorting

\section{INTRODUCTION}

Bengali is an eastern Indo-Aryan Language. It is the native language of Bangladesh, the Indian state of West Bengal and parts of the Indian states of Tripura and Assam. It is written with the Bengali script. ${ }^{[1]}$ About 181 million people are the native speaker of this language and nearly 250 million people can speak Bengali in total. It is one of the most spoken languages (ranking sixth) all over the world. ${ }^{[2]}$ It is the national and official language of Bangladesh and one of the 23 official languages recognized by the Republic of India. ${ }^{[1]}$ It is the official language of the states of West Bengal and Tripura. ${ }^{[1]}$ It is also a major language in the Indian union territory of Andaman and Nicobar Islands. ${ }^{[1]}$ It was made an official language of Sierra Leone in order to honor the Bangladeshi peacekeeping force from the United Nations stationed there. ${ }^{[1]}$ It is also the co-official language of Assam.

As the Bengali language is a rich and widely used language, it must have some standardization such as Bengali keyboard layout, Bengali character recognition, voice synthesis etc. But unfortunately we have advanced a very little in this regard. In a rapidly developing environment of computerization of Bengali language, one of the most important issues is Bengali text sorting. For the development of Bengali database systems, an efficient, versatile sorting algorithm is a must. There are some papers on this topic but none of them could set standard for sorting Bengali text. In this paper, we have shown the analysis of the previously proposed sorting algorithms and the comparison among the procedures to represent drawbacks, difficulties and limitations. Based on these observations we have proposed an algorithm based on Unicode to sort Bengali strings accurately, and the complexity is satisfying. The proposed algorithm is readable and very easy to code; hence it has the potential to be considered as standard algorithm for sorting Bengali strings. As Bangla Academy ${ }^{[3]}$ is the national academy for promoting Bangla language in Bangladesh, we are following the Bangla Academy dictionary standard for our proposed method.

\section{THE BENGALI LANGUAGE}

Base Letters: In the written form of Bengali alphabets, there are 11 vowels and 39 consonants. When we use these alphabets, we call it base letters. The vowels are

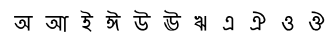

The consonants are

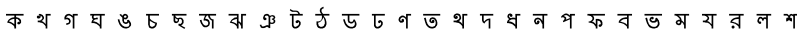

$$
\begin{aligned}
& \text { य ग ড ঢ़ য় }
\end{aligned}
$$

These are the base letters of Bengali language.

Modifiers: There two types of modifiers in Bengali, vowel modifiers and the consonant modifiers.

10 of the 11 vowels can be used as modifier to the consonants. We call them vowel modifier. They can never be used

\begin{tabular}{|c|c|c|}
\hline Word & Vowel Modifier & Example \\
\hline অ & - & কলম / kolom/ \\
\hline आ & া & কলাম / kJlam/ \\
\hline ই & ि & भিঠা / pit ${ }^{\mathrm{h}}$ a / \\
\hline
\end{tabular}
independently. Here is the list of vowel modifier: 


\begin{tabular}{|c|c|c|}
\hline के & ो & জীবন / dzībon / \\
\hline উ & a & তুলা /tula / \\
\hline ঊ & 2 & সূচী / suci / \\
\hline ¥ & ? & বৃষ্টি /briSti/ \\
\hline$a$ & ) & কেমন / kæmon/ \\
\hline 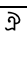 & ? & হুম / hojmo/ \\
\hline 3 & बা & কোমল / komol/ \\
\hline 3 & ओ & শৌখিন / Sowk ${ }^{h} \mathrm{in} /$ \\
\hline
\end{tabular}

Table-01: Vowel Modifiers

Like the vowel modifiers, the consonants have some short forms when they used with other consonant. They are called - एला. Some of them are given below:

\begin{tabular}{|c|c|c|}
\hline Word & Consonant Modifier & Example \\
\hline ব & ব-ফना & অ্বর / dzכr/ \\
\hline य & य-ফলा & জন্য / dzonno/ \\
\hline র & র-ফला & তীব্র / tibro/ \\
\hline
\end{tabular}

Table-02: Consonant Modifiers

Compound Characters: When two or more consonant characters of Bengali alphabet used together, then they are called the compound characters. There are about 270 compound characters in Bengali. Some examples of compound characters are given below:

\begin{tabular}{|c|c|c|c|}
\hline Word & $\begin{array}{l}\text { Compound } \\
\text { Character }\end{array}$ & $\begin{array}{c}\text { Decompressed } \\
\text { Form }\end{array}$ & $\begin{array}{c}\text { No. of } \\
\text { Alphabet } \\
\text { Used }\end{array}$ \\
\hline উত্ত্বল / ujjbol/ & $\sqrt{\sqrt{4}}$ & ऊ + ऊ + व & 3 \\
\hline বৃষ্টি /briSti / & छे & य + ট & 2 \\
\hline $\begin{array}{c}\text { यूদ্ধ } \\
\text { / dzuddho/ }\end{array}$ & $\overline{4}$ & $দ+\varepsilon$ & 2 \\
\hline $\begin{array}{c}\text { ज্রাহ্মন } \\
\text { /brammon/ }\end{array}$ & क्म & হ + म & 2 \\
\hline
\end{tabular}

\begin{tabular}{|c|c|c|c|}
\hline $\begin{array}{c}\text { সম্বন্ধে } \\
/ \text { sommond }{ }^{\mathrm{h}} \mathrm{e} \\
/\end{array}$ & $\begin{array}{l}\text { व্ব } \\
\text { ब্ধ }\end{array}$ & $\begin{array}{l}\text { म }+ \text { ব } \\
\text { न }+ \text { ধ }\end{array}$ & $\begin{array}{l}2 \\
2\end{array}$ \\
\hline
\end{tabular}

Table-03: Compound Characters

\section{DIFFICULTIES OF SORTING BENGALI TEXT}

The problem associated with sorting of Bengali words are as follows-

- Bengali words should be sorted according to the Bangla Academy ${ }^{[4]}$ standard. But unfortunately the Unicode for Bengali characters are not in Bangla Academy dictionary order. So, mapping is required to sort words uniquely.

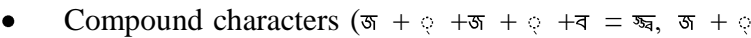
+ ऊ $=$ ऊ) make Bengali sorting complicated.

- In writing, vowel modifiers $($ ? + क $=$ েक, क + ा $=$ का $)$ can precede or follow the base letter in Bengali words, but in computation it should be placed after the base letter for proper sorting.

- Unicode characters র, য়, ঢ়, ড় can be written in two ways. For example, $\square$ can be a single character $\square$ (lu09DD) or compound of $\tau+$ (lu09A2+lu09BC). These two cases should be considered as special case while sorting.

\section{POSSIBLE SOLUTIONS}

\subsection{Method 1}

M. Shahidur Rahman et al. ${ }^{[5]}$ have proposed an alternative representation during computation. According to their proposal a dummy character is placed after the character, which does not have any modifier. Moreover, it is also considered that there would be no dummy character between the constituent parts of a compound character. Generally vowel modifiers can be typed before or after the characters but for this algorithm the modifiers are shifted after the character for the internal representation while computing. In case of compound characters, they are decomposed into their constituent components and stored accordingly. In Table-4 internal representation of few words are shown where $\square$ represents the dummy character. To sort the words the relative order in the character set are arranged in the following way-

Null modifier $<$ Vowel Modifiers $<$ Vowels $<$ Consonants

\begin{tabular}{|c|c|c|}
\hline $\begin{array}{l}\text { Input } \\
\text { Word }\end{array}$ & $\begin{array}{l}\text { Internal input } \\
\text { Representation }\end{array}$ & $\begin{array}{l}\text { Internal Representation } \\
\text { of Sorted Output Word }\end{array}$ \\
\hline কুসুম & ক স ম ম & 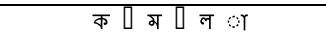 \\
\hline निলয় & न ि ल ए ग़ & क द স म \\
\hline মৃণाल & म२ ণ ल ल & थ । क प न \\
\hline
\end{tabular}




\begin{tabular}{|c|c|c|}
\hline থোকন & श ॥ क [ न & न ि ल [য় \\
\hline कमला & क [ म [ ल া & म? भा ल \\
\hline রেশমা & র । শ म मा & র ০ শ [ ম া \\
\hline
\end{tabular}

Table-04: Internal representation Of Words In ${ }^{[5]}$

This method has the following drawbacks:

- This work is based on ASCII based Bengali words.

- In this procedure, इসন্ত () is not considered.

\subsection{Method 2}

According to Mafizul Haque Khan et al.'s “An Efficient And Correct Bangla Sorting Algorithm" [6] a character is represented with two digit unique number for every letter of Bengali alphabet along with the vowel modifiers and the consonant modifiers. The letters and their corresponding numbers are given in Table-05. It is to be noticed that here 'আ ' is treated as a set of two characters that is ' $অ+$ r'. The consonant modifiers are having the same number as their original consonants.

\begin{tabular}{|c|c|}
\hline Character & Number \\
\hline অ, ই-ঔ, :, & $11-23$ \\
\hline ক-ঙ, চ- & $25-34$ \\
\hline ট, ঠ, ড, ড়, ঢ, ঢ़, ศ, [] & $35-42$ \\
\hline ত, থ, দ, ধ, ন, भ, ফ, ব, ভ, ম & $43-52$ \\
\hline य, য়, ₹, র, ব,ল, শ, ষ, স & $53-61$ \\
\hline 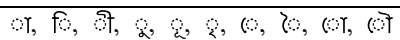 & $71-80$ \\
\hline
\end{tabular}

Table-05: Representing A Bengali Character Of Two Digit

For vowel modifiers, wherever its position is (i.e. Left, Right or Down), its corresponding number will always be visual after the number of the letter over which it was applied. For Example, the words সা, मि, সু, সো, and ग change into numbers '6171','6174','6172','6179' and '6177'. For Compound

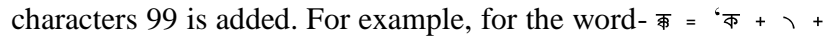
क', the number will be 259925 . For সशु, it will be - 60619953 . The difference of number of digit between the words গোধূল (277946755773) and সংস্কৃতি (6021609925764372) is 4. So according to the algorithm, four zero's are appended at the end of the number representing গোধূলি. So finally the number becomes 2779467557730000.

\section{Drawbacks-}

- $\quad$ आ is considered only as a compound character of অ + ', which is incorrect.
- The sequence of characters does not maintain the sequence of Bangla Academy ${ }^{[4]}$.

- Adding extra zero's at the end of the number with less digit which increases overhead.

\subsection{Method 3}

Shah Md. Emrul Islam et al. proposed a method to Sort Unicode Bengali Text Using Ancillary Maps. ${ }^{[7]}$ In this method, the Unicode characters are mapped and given a Sort Weight. The structure of the Ancillary table is like the following:

\begin{tabular}{|c|c|c|}
\hline Unicode & Sort Weight & Remarks \\
\hline 0985 & 01 & \\
\hline 0986 & 02 & RM \\
\hline $09 \mathrm{BE}$ & 03 & \\
\hline 0987 & 04 & LM \\
\hline $09 \mathrm{BF}$ & 05 & \\
\hline$\cdot$ & $\cdot$ & $\mathrm{BL}$ \\
\hline$\cdot$ & 56 & $\mathrm{BL}$ \\
\hline $09 \mathrm{~B} 6$ & 57 & \\
\hline $09 \mathrm{~B} 7$ & & \\
\hline$\cdot$ & & \\
\hline $09 \mathrm{FA}$ & & \\
\hline $09 \mathrm{BD}$ & & \\
\hline
\end{tabular}

Table-06: Structure of Ancillary Maps

For each word the mapped value are concatenated and a decimal point is added after two digits from the starting. Then it becomes a floating point number. By comparing all the floating point numbers, the list of words is sorted. For example, the word কানকো (Unicode Representation 099509BE09A8099509CB) gets the value 25.0346002519

The algorithm uses the decimal number system for determination of the value of a Bengali Word. There is an example for two Bengali words "কর্মচারী" and "কार्यकরভाবে", the decimal value becomes 25.005463510030035407 and 25.03546352002500540050034915 respectively. Now it's easy to compare the two numbers. By this way a list of Bengali words can be sorted. 


\section{Drawbacks}

- Adds extra complexity while converting a string to floating point number

- $\quad$ The range for the floating point decimal number may exceed if the length of the word is much longer which will arise round-off error

\section{PROPOSED SOLUTION}

\subsection{Main Process}

In our proposed method, at first we mapped all the characters that are used in Bengali text according to Bangla Academy ${ }^{[4]}$ sequence.

At the first stage of word processing, an extra dummy character is being added after the base letter which has no modifier. But if there is a vowel modifier with the base letter then we place that modifier in place of the dummy character. For example, if we have a word “कलाम", then we make it क+ ल्मा+ म. If there is no vowel modifier at the end of the last letter then the null modifier is not added. When we consider a compound character, then we get the base letter, a link character (), and then the next character of the compound character and so on. For example, the word यूक्了, we get $য+$ क + + $+\overline{+}$. This procedure is also maintained for the letters with consonant modifier. Hence the alternative representation of the Bengali string is obtained.

In the next step, we generate a string of digits for each Bengali string using the map table (Table-07) to obtain a secondary representation. Then we sort these strings using MergeSort or any other efficient sorting algorithm using string comparison. Finally, we convert the secondary representations to its original Bengali strings.

The rules followed in our approach are-

1. Any character without any modifier is considered as character followed by null modifier.

2. Any character with by vowel modifier is considered as character followed by vowel modifier.

3. Any character with consonant modifier is considered as character followed by link character followed by consonant.

4. Any compound character is considered as character followed by link character followed by character.

In our algorithm the precedence of the Bengali character is maintained using the following rule:

Dummy/Null Character $<$ Vowel Modifier $<$ Consonant Modifier $<$ Vowel $<$ Consonant

\subsection{Mapping}

The whole mapping (Bengali character to a pair of digits) is given in the table below:

\begin{tabular}{|c|c|c|}
\hline Unicode & Character & Value \\
\hline 09F9 & $\circ$ & 01 \\
\hline 09BE & ा & 02 \\
\hline 09BF & ि & 03 \\
\hline 09C0 & हो & 04 \\
\hline 09C1 & 2 & 05 \\
\hline 09C2 & a & 06 \\
\hline 09C3 & ? & 07 \\
\hline 09C7 & 。 & 08 \\
\hline 09C8 & ? & 09 \\
\hline 09CB & ा & 10 \\
\hline 09CC & को & 11 \\
\hline 09CD & 8 & 12 \\
\hline 0985 & ज & 13 \\
\hline 0986 & आ & 14 \\
\hline 0987 & रे & 15 \\
\hline 0988 & मे & 16 \\
\hline 0989 & উ & 17 \\
\hline 098A & ঊ & 18 \\
\hline 098B & ঋ & 19 \\
\hline $098 \mathrm{~F}$ & $a$ & 20 \\
\hline 0990 & 9 & 21 \\
\hline 0993 & 3 & 22 \\
\hline 0994 & ঔ & 23 \\
\hline 0982 & a & 24 \\
\hline 0983 & : & 25 \\
\hline 0981 & \% & 26 \\
\hline 0995 & क & 27 \\
\hline 0996 & थ & 28 \\
\hline 0997 & গ & 29 \\
\hline 0998 & घ & 30 \\
\hline 0999 & \& & 31 \\
\hline 099A & $\bar{E}$ & 32 \\
\hline 099B & इ & 32 \\
\hline 099C & ज & 33 \\
\hline 099D & ж & 34 \\
\hline 099E & $\Re$ & 36 \\
\hline 099F & ট & 37 \\
\hline 09A0 & $\delta$ & 38 \\
\hline 09A1 & ড & 39 \\
\hline 09DC & ড় & 40 \\
\hline 09A2 & E & 41 \\
\hline 09DD & 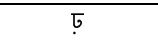 & 42 \\
\hline 09A3 & ศ & 43 \\
\hline 09CE & ए & 44 \\
\hline 09A4 & $\bar{\sigma}$ & 45 \\
\hline 09A5 & श & 46 \\
\hline 09A6 & 5 & 47 \\
\hline 09A7 & $\varepsilon$ & 48 \\
\hline
\end{tabular}




\begin{tabular}{|c|c|c|}
\hline Unicode & Character & Value \\
\hline 09A8 & न & 49 \\
\hline 09AA & भ & 50 \\
\hline 09AB & क & 51 \\
\hline 09AC & ব & 52 \\
\hline 09AD & ভ & 53 \\
\hline 09AE & म & 54 \\
\hline 09AF & य & 55 \\
\hline 09DF & ग़ & 56 \\
\hline 09B0 & র & 57 \\
\hline 09B2 & ल & 58 \\
\hline 09B6 & $x$ & 59 \\
\hline 09B7 & य & 60 \\
\hline 09B8 & স & 61 \\
\hline 09B9 & 5 & 62 \\
\hline 09BC & ? & 63 \\
\hline
\end{tabular}

Table-07: Our Proposed Map Values (According to the Bangla Academy Sequence $\left.{ }^{[4]}\right)$

\subsection{Steps for Sorting Bengali Text}

Step 1: At first, for each word a string is generated with dummy characters where needed. Here we represent the following words with their internal representations:

\begin{tabular}{|c|c|}
\hline Input word & $\begin{array}{c}\text { Internal } \\
\text { Representation }\end{array}$ \\
\hline আমার / amar / & আ॰ म র \\
\hline কলাম / kJlam/ & क० ला ম \\
\hline यूক্ত / dzukto / & यूक ब \\
\hline কलম / kolom/ & क。ल०म \\
\hline ধন্য / dhonyo/ & ধ०ন १ य \\
\hline আम /aam/ & আ०म \\
\hline
\end{tabular}

Here the dummy character is '。'.

Step 2: Each of the Unicode character will be represented with string of two digits from the map. For the previous example, the representation of Unicode characters is given below:

\begin{tabular}{|c|c|c|}
\hline Input word & $\begin{array}{c}\text { Internal } \\
\text { Representation }\end{array}$ & $\begin{array}{l}\text { Representing with } \\
\text { mapped value }\end{array}$ \\
\hline আমার / amar/ & আ॰ म র & 1401540257 \\
\hline কলाম / kJlam/ & क० ল া ম & 2701580254 \\
\hline यুক্ত / dzukto/ & यूक ত & 5505271245 \\
\hline কलম / kJlom/ & क॰ल॰ म & 2701580154 \\
\hline ধন্য /dhonyo/ & ध०न १य & 4801491255 \\
\hline আम / aam/ & आ॰ म & 140154 \\
\hline
\end{tabular}

Step 3: Now these generated strings can be sorted using any efficient sorting algorithm. After sorting the words of previous example we get the following order:

\begin{tabular}{|c|c|c|}
\hline Input word & $\begin{array}{c}\text { Internal } \\
\text { Representation } \\
\end{array}$ & $\begin{array}{c}\text { Representing with } \\
\text { mapped value }\end{array}$ \\
\hline আম / $\mathrm{aam} /$ & আ॰ ম & 140154 \\
\hline আমার / amar/ & आ。 & 1401540257 \\
\hline কলম / kolom/ & क॰ल० म & 2701580154 \\
\hline কলাম / kJlam/ & क。ल ा म & 2701580254 \\
\hline ধন্য / dhonyo/ & ध० न य & 4801491255 \\
\hline যুক্ত / dzukto/ & यूक ত & 5505271245 \\
\hline
\end{tabular}

Step 4: In this step, we retrieve the sorted Bengali words by reverse mapping.

\subsection{Algorithm}

The proposed algorithm for sorting Bengali words is given below-

1. $\mathrm{N} \leftarrow$ Total no of words

2. for $\mathrm{i} \longleftarrow-1$ to $\mathrm{N}$

3. For each word derive MappedString

4. Sort the Array containing MappedStrings

5. for $\mathrm{i} \longleftarrow 1$ to $\mathrm{N}$

6. Reverse map the Bengali words from each MappedString $_{\mathrm{i}}$

\subsection{BengaliSort API}

We have implemented our proposed technique in JAVA and created an API for sorting Unicode Bengali words using this algorithm. This API contains the classes BengaliSort, MapDefine, SortWords, MergeSort, QuickSort, RadixSort.

To sort words one of the methods below of class BengaliSort has to be called.

- $\quad$ void sort(String[] string)

- $\quad$ void $\operatorname{sort}($ Collection $<$ String $>$ collection)

- $\quad$ void $\operatorname{sort}($ Collection $<$ String $>$ collection, int fromIndex, int toIndex, boolean WithoutRepeatition)

- void sort(String string[], int fromIndex, int toIndex, boolean WithoutRepeatition)

- $\quad$ void sort(String string[], boolean WithoutRepeatition)

- void sort(Collection<String> collection, boolean WithoutRepeatition)

The link for the downloadable BengliSort API http://www.msoden.com/

\subsection{Complexity} Mapping and Reverse Mapping Function

$\mathrm{N}=$ total number of word in list or input list.

Mapping and reverse mapping is done in linear time. So, the Complexity of conversion from Unicode characters to integer string is $\mathrm{O}(\mathrm{N})$. The complexity of reverse mapping is also $\mathrm{O}(\mathrm{N})$. 


\section{Sorting}

Complexity of MergeSort for $\mathrm{N}$ words $=\mathrm{O}(\mathrm{N} \log (\mathrm{N}))$

$\begin{aligned} \text { So, } \text { Total Complexity } & =\mathrm{O}(\mathrm{N})+\mathrm{O}(\mathrm{N} \log (\mathrm{N}))+\mathrm{O}(\mathrm{N}) \\ & \approx \mathbf{O}(\mathrm{N} \log (\mathbf{N}))\end{aligned}$

6. COMPARISON

Runtime Comparison

\begin{tabular}{|c|c|c|c|}
\hline $\begin{array}{c}\text { Proced- } \\
\text { ures }\end{array}$ & $\begin{array}{c}\text { Proposed } \\
\text { Approach }\end{array}$ & $\begin{array}{l}\text { An Efficient } \\
\text { And Correct } \\
\text { Bangla } \\
\text { Sorting } \\
\text { Algorithm }\end{array}$ & $\begin{array}{l}\text { An Approach to } \\
\text { sort Unicode } \\
\text { Bengali Text } \\
\text { Using Ancillary } \\
\text { Maps }^{\text {Nof }}\end{array}$ \\
\cline { 1 - 2 } & $94 \mathrm{~ms}$ & $93 \mathrm{~ms}$ & $16 \mathrm{~ms}$ \\
\hline 50000 & $281 \mathrm{~ms}$ & $296 \mathrm{~ms}$ & $63 \mathrm{~ms}$ \\
\hline 10000 & $546 \mathrm{~ms}$ & $609 \mathrm{~ms}$ & $156 \mathrm{~ms}$ \\
\hline 500000 & $2730 \mathrm{~ms}$ & $2980 \mathrm{~ms}$ & $686 \mathrm{~ms}$ \\
\hline 1000000 & $5756 \mathrm{~ms}$ & $5632 \mathrm{~ms}$ & $1498 \mathrm{~ms}$ \\
\hline
\end{tabular}

Table-8: Runtime Comparison

\section{OUTCOMES}

Comparison in Table-08 shows that, the runtime for "An Efficient And Correct Bangla Sorting Algorithm ${ }^{[6] " ~ i s ~ a l m o s t ~}$ same as ours. But the proposed mapping does not maintain the sequence of Bangla Academy Dictionary ${ }^{[4]}$. For the approach described in "An Approach to sort Unicode Bengali Text Using

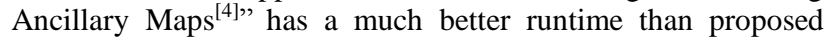
approach because it compares floating point of Bengali words. But this approach has a major problem of round-off error. Above all, the character sequence of the approach is not according to Bangla Academy dictionary ${ }^{[4] .}$ The paper "Bangla Sorting Algorithm: A Linguistic Approach" ${ }^{[5]}$ is ASCII based approach, so we did not consider this paper to compare with other approaches. We proposed a standard approach considering these drawbacks.

We have sorted the Bengali words using string comparison. This maintains the Bangla Academy ${ }^{[4]}$ dictionary sequence. So far, string comparison has not yet been proposed by any other approach and our total complexity is satisfying. So, our algorithm can be considered as a standard one.

\section{CONCLUSION}

In this paper we have proposed an efficient and proper way to sort Bengali strings that conforms with the proper structure of Bengali words i.e. each modifier comes with a base letter. Our main effort was to maintain the right order according to the standard set by Bangla Academy while sorting and to preserve the general complexity of standard sorting algorithm. We have also tested the algorithm with more than 56,000 data taken randomly from Samsad Bengali-English Dictionary ${ }^{[15]}$ in our algorithm and the output is completely in proper sequence as represented in Bangla Academy Dictionary. So this algorithm has the potential to be considered as the standard procedure for sorting Bengali strings based on Unicode character.

\section{REFERENCES}

[1] http://en.wikipedia.org/wiki/Bengali_language Retrieved 2011-05-11

[2] http://en.wikipedia.org/wiki/List_of_languages_by_number _of_native_speakers Retrieved 2011-05-11

[3] Bangla Academy: http://en.wikipedia.org/wiki/Bangla_ Academy

[4] Bangla Academy Bengali-English Dictionary, First Edition June, 1994, Bangla Academy, Dhaka, Bangladesh.

[5] Rahman, Md. Shahidur and Iqbal, Md. Zafar, "Bangla Sorting Algorithm: A Linguistic Approach". Proceedings of International Conference on Computer and Information Technology, Dhaka, 18-20 December 1998, pp. 204-208.

[6] Mafizul Haque Khan, S M Rafizul Haque, Md. Sharif Uddin, Rahat Khan, A B M Tariqul Islam, "An Efficient And Correct Bangla Sorting Algorithm" $7^{\text {th }}$ ICCIT, 2004 Page 125

[7] Shah Md. Emrul Islam and Muhammad Masroor Ali "An Approach to Sort Unicode Bengali Text Using Ancillary Maps”, BUET, Dhaka.

[8] Cormen, Thomas and Leiserson, Charles and Rivest, Ronald: "Introduction to Algorithm", Prentice - Hall of India Private Limited, 1999.

[9] Ellis Horowitz and Sartaz Shani,: "Fundamentals of Computer Algorithm", Galgotia Publications Limited.

[10] Unicode http://www.unicode.org/charts/PDF/U0980.pdf

[11] Mohammad, Kazi Din: "Adhunik Bangla Byakoron O Rochona"

[12] Rajesh Palit, Md. Abdus Sattar, "Representation of Bangla Characters in the Computer Systems", Bangladesh Journal of Computer and Information Technology, Vol. 7, No. 1, December, 1999.

[13] Masum, Md. Salahuddin, "Study of Bangla Conjunctive Characters for Recognition", B.Sc.Engg.Thesis, department of Computer Scince and Engineering, BUET, August 2001.

[14] Deitel and Santry “Advanced Java 2 Platform”, Prentice Hall Publications.

[15] Knuth, Donald "The Art of Computer Programming", Addison-Wisely Publications, Boston

[16] Samsad Bengali-English Dictionary http://dsal.uchicago.edu/dictionaries/biswas-bengali/

[17] Ishida, Richard - Bengali script notes http://rishida.net/scripts/bengali/ 